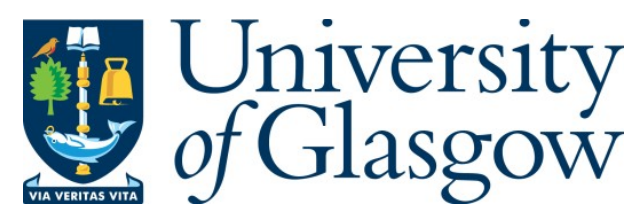

Spanos, D., Hankey, C., and Melville, C. (2016) The effectiveness of a weight maintenance intervention for adults with intellectual disabilities and obesity: a single stranded study. Journal of Applied Research in Intellectual Disabilities, 29(4), pp. 317-329.

There may be differences between this version and the published version. You are advised to consult the publisher's version if you wish to cite from it.

http://eprints.gla.ac.uk/115255/

Deposited on: 11 March 2016

Enlighten - Research publications by members of the University of Glasgow http://eprints.gla.ac.uk 


\title{
The Effectiveness of a Weight Maintenance Intervention for Adults with Intellectual Disabilities and Obesity: A Single Stranded Study
}

\author{
2 Dimitrios Spanos*, Catherine R. Hankey ${ }^{\dagger}$ and Craig A. Melville* \\ *Institute of Mental Health $\mathcal{E}$ Wellbeing, College of Medical Veterinary and Life Sciences, University of Glasgow, Glasgow, UK; ${ }^{\dagger}$ College of \\ 3 Medical, Veterinary and Medical and Life Sciences, University of Glasgow, Glasgow Royal Infirmary, Glasgow, UK
}

1 Accepted for publication $x x x x$

Background The evidence base for weight management programmes incorporating a weight loss and a weight maintenance phase for adults with intellectual disabilities (ID) is limited. This study describes the weight maintenance phase of a multicomponent weight management programme for adults with intellectual disability and obesity (TAKE 5).

Materials and Methods Thirty-one participants who had completed the 16 week TAKE five weight loss intervention (Phase I) were invited to participate in a 12 month weight maintenance intervention (Phase II). Content included recommendations of the National Weight Control Registry.
Results Twenty-eight participants completed Phase II with $50.4 \%$ maintaining their weight (mean weight change $-0.5 \mathrm{~kg}, \mathrm{SD} 2.2$ ), $28.7 \%$ gaining weight (mean weight gain $5.4 \mathrm{~kg}, \mathrm{SD} 2.2$ ) and $21.6 \%$ losing weight (mean weight loss $-8.0 \mathrm{~kg}$, SD 3.0) at 12 months.

Conclusion Further research is justified to investigate the efficacy of weight loss maintenance interventions in adults with intellectual disability and obesity, using controlled study designs.

Keywords: intellectual disabilities, obesity, single stranded, weight maintenance, weight management

\section{Definition of weight maintenance}

Although there is considerable evidence to guide best practice in weight loss, much less is known about how people can sustain intentional weight loss over the long term (Stevens et al. 2006). The National Weight Control Registry (NWCR) is one of the few sources of information on weight maintenance in adults without intellectual disability and suggests that individuals are more likely to maintain their weight loss for at least a year when they monitor their weight at least once a week, continue to eat a low fat or low calorie diet, maintain a consistent eating pattern, be active by exercising for $1 \mathrm{~h} /$ day and reduce inactivity by watching $<10$ h of TV per week (Wing \& Phelan 2005).

However, there are no universally accepted definitions of successful weight maintenance (Stevens et al. 2006) and clinical guidelines do not clearly define weight maintenance (NICE 2006; SIGN 2010). Weight maintenance has been defined 'either in relation to weight losses previously achieved or in terms of 
absolute or percentage weight change at points successively more distant in time' (Jeffery et al. 2000).

Stevens et al. (2006) identified the factors that lead to small fluctuations of weight at different points of measurement (e.g. measuring weight during menstrual cycle or after a physical activity, different clothing worn by the participants at the different points of measurement, meal consumption prior to the measurements) and defined weight maintenance as 'a weight change of $<3 \%$ of a designated body weight under standardized conditions'.

\section{Weight maintenance interventions in adults with intellectual disability}

Obesity can be an important health issue for adults with intellectual disability (Hove 2004; Braunschweig et al. 2004; Maaskant et al. 2009), and evidence consistently shows that the prevalence of obesity can be equally high as in the general population (Stancliffe et al. 2011) or even higher than in the general population (Yamaki 2005; Robertson et al. 2014). However, there is a wide range of reported estimates, namely from 2 to $50.5 \%$, for the levels of obesity in adults with intellectual disability (Haveman et al. 2010). Similar, to the general population, in adults with intellectual disability weight gain can be attributed to unhealthy dietary habits (Draheim et al. 2002), a high prevalence of inactivity and sedentary lifestyles (Havercamp et al. 2004; Bartlo \& Klein 2011) but also to determinants associated to intellectual disability such as genetic pre-disposition (Farooqi \& O'Rahilly 2005), use of psychotropic medication known for their obesogenic effects (Robertson et al. 2000) and type of living arrangements such as living in restrictive versus less restrictive environments (Rimmer \& Yamaki 2006). In addition, adults with intellectual disability are more susceptible to the health risks associated to obesity such as coronary heart disease and diabetes (Draheim 2006; Straetmans et al. 2007) than the general population because they are also more likely to be exposed to health inequalities as a result of the ineffectiveness of health services to meet their needs (Robertson et al. 2014).

The evidence on the effectiveness of weight loss interventions in adults with intellectual disability is limited, and there is even less evidence to guide weight maintenance interventions for adults with intellectual disability after weight loss. According to a recent

4 systematic review by Spanos et al. (2013a,b), only four of 22 identified weight management studies for adults with intellectual disability offered a structured weight loss maintenance phase. The limited number of studies and the poor methodological quality among the studies (e.g. inadequate sample sizes, poor reporting on components of weight maintenance) do not allow valid recommendations for an effective weight maintenance approach in adults with intellectual disability to be made.

This study presents the findings of a 12 month weight maintenance intervention comprising the second phase of the TAKE 5 multicomponent weight management programme for adults with intellectual disability and obesity (Melville et al. 2011). The two main research questions for the second phase of the weight management programme examined were whether participants achieve:

1. Do participants with intellectual disability in a multicomponent weight maintenance intervention achieve to maintain their weight loss (a weight change of $<3 \%$ )?

2. Does a multicomponent weight loss maintenance intervention increase the level of physical activity to a significant level?

\section{Materials and Methods}

\section{Study design}

The TAKE 5 weight maintenance programme was a 12 month single stranded study. TAKE 5 was conducted according to the guidelines laid down in the Declaration of Helsinki. In keeping with the Adults with Incapacity (Scotland) Act 2000 (Scottish Executive 2000), all procedures involving human subjects/patients were approved by the Scotland Research Ethics Committee A and the relevant local research ethics committee (2009). Written informed consent was obtained from all participants or next of kin/welfare guardian.

\section{Participants}

Potential participants in Phase I of the TAKE 5 weight management programme, described in detail in Melville et al. (2011), were service users over 18 years old, with mild, moderate, severe or profound intellectual disability, identified as having obesity (BMI $\geq 30 \mathrm{~kg} /$ $\mathrm{m}^{2}$ ), ambulatory and requesting support with weight loss by themselves or by their carers. These participants had been referred to intellectual disability specialist dietitians of the NHS Glasgow Learning Disability Partnership by general practitioners (family physicians) in primary care or by other specialist intellectual 
disability professionals. Information sheets were sent to individuals that met the inclusion criteria to take part to a weight management intervention for adults with intellectual disability. Participants completing the 16 week weight loss intervention (Phase I) of the TAKE 5 , were invited to join the 12 month weight maintenance phase (Phase II), provided that they had lost a minimum of $3 \%$ weight loss. Thirty-one adults with intellectual disability were eligible to participate in Phase II having completed Phase I of TAKE 5 and achieved a weight loss $\geq 3 \%$ of initial body weight and reported not planning further intentional weight loss at present.

\section{Weight maintenance definition}

The goal of Phase II was weight maintenance. Weight maintenance in this study was defined as 'a weight change of $<3 \%$ of a designated body weight under standardized conditions' (Stevens et al. 2006). In this study designated body weight was defined as the weight immediately after a weight loss period of 16 weeks.

\section{The TAKE 5 weight maintenance intervention}

The TAKE 5 weight maintenance intervention was based on the recommendations of the National Weight Control Registry (NWCR), and the content of the sessions was based on the 12 monthly group sessions delivered at the Glasgow and Clyde Weight Management Service (GCWMS) (Morrison et al. 2012). However, the intervention was adapted and changed based on the ability levels of the participants with intellectual disability.

5 The intervention was delivered by a dietitian specialized in working with adults with intellectual disability and comprised 12 monthly (one session every 4 weeks for 12 months), individualized one to one sessions (40-50 min each). Sessions took place in the house of most participants but for two participants the intervention was delivered at a day centre the participants attended (due to insufficient space at home). Augmentative communication strategies ('Talking Mats') were incorporated where relevant (Brewster 2004) using pictures of clip arts of people doing activities and photos of foods, food models and fat and muscle models used to facilitate understanding.

The intervention also included once monthly contact via telephone with either the participants or with the carers who supported them, depending on the ability levels of the participants. The purpose of the monthly telephone contacts was used to:

1. Recap the main points of the previous sessions.

2. To provide ongoing motivation.

3. Support problem solving.

\section{Dietary advice}

Each participant was offered an energy prescription diet to maintain their weight, following the same principles used in the TAKE 5 weight loss intervention but without an energy deficit of 600 kilocalories (kcal) per day (Melville et al. 2011). This prescription was based on estimated total energy expenditure for each participant using the Schofield equations for basal metabolic rate, combined with an activity factor adapted from World Health Organisation (1985). Individual prescriptions ranged between 1800 and $3500 \mathrm{kcal}$ (7536 kilojoule $(\mathrm{kJ})$ to $14654 \mathrm{~kJ}$ ) daily.

The prescribed diet provided daily caloric intake from a specified number of daily portions of foods based on the recommendations of the 'eatwell plate' issued by the Government of the United Kingdom. Therefore, the prescribed diet was split up into six different food groups:

1. Starches (bread, other cereals and potatoes).

2. Fruit and vegetables (fresh, frozen, canned and dried).

3. Dairy (milk, cheese, yogurt).

4. Meat fish and alternatives (meat, poultry, fish, eggs, legumes and pulses).

5. Fat allowance (margarine, butter, olive oil and other spreads).

6. Extra allowance (foods and drinks containing sugar). Starches made up the largest part of the diet (33\%), followed by fruit and vegetables (33\%), milk and dairy foods (15\%), meat fish and alternatives (12\%), foods and drinks high in sugar and fat (8\%). Overall, the individualized prescribed diet aimed to ensure that $50 \%$ of daily energy intake was from carbohydrates, $<35 \%$ from fats and $<20 \%$ from protein, and necessary micronutrients (Scientific Advisory Committee on Nutrition 2011).

\section{Physical activity}

The advice delivered on physical activity in TAKE 5 weight maintenance was based on the recommendations of clinical guidelines and studies supporting the importance of physical activity in the maintenance of reduced weight (NICE 2006; Catenacci \& Wyatt 2007; 
SIGN 2010). This guidance suggests that people who have been obese and who have lost weight should be advised that they may need to do at least 60 minutes of moderate-intensity activity a day to sustain their weight loss (NICE 2006; Catenacci \& Wyatt 2007; SIGN 2010). It was recognized that the participants in this study were quite far away from this level of activity (Matthews et al. 2011; Melville et al. 2011). Therefore, participants were supported to gradually increase their levels of physical activity in small increments; initially, working towards the public health recommendation of $30 \mathrm{~min}$ of moderate-intensity activity on 5 days a week (Chief Medical Officer 2011).

\section{Behaviour change techniques}

Self-monitoring has been shown to be a key behaviour change technique for effective weight management (Michie et al. 2009). Based on research evidence (Wing \& Phelan 2005) and best practice recommendations for clinical practice (SIGN 2010), participants were asked to record their weight once per week. Regular weight monitoring provides an opportunity for individuals to reflect on how their lifestyle is affecting their weight and allows individuals to take action before weight changes significantly (Butryn et al. 2007). In individuals with intellectual disability, monitoring of the weight may require the support of the carers. Therefore, in session 1, the participants were supported from the dietitian and the carers to set the limits of healthy weight fluctuation based on the definition of Stevens et al. (2006), and they were asked to aim not to surpass these limits.

Participants were supported to continue with their weight management using additional behavioural change techniques used in the Phase I including goal setting, self-monitoring using food and activity diaries, relapse prevention strategies, stimulus control, assertiveness and problem solving (Melville et al. 2011).

\section{The role of carers}

Social support is very important in weight management and can have the form of emotional, instrumental, informational and appraisal support (Verheijden et al.

6 2005). This support can come from family members, friends and colleagues and in the case of people with intellectual disability sometimes from paid carers. Carers supporting adults with intellectual disabilities have been shown to have an important influence on successful weight management (Spanos et al. 2013a,b).
During the TAKE 5, Phase II carers were encouraged to attend the sessions and were asked to:

1. Encourage and appreciate even minor changes in a participant's lifestyle.

2. Ensure that a participant takes an active role in making lifestyle changes.

3. Promote realistic changes in diet and activity if needed.

4. Support participants to keep weight records as part of the behaviour approach technique. These weight records were not used in the analysis of the study outcomes.

\section{Study outcomes}

1. Change in weight $(\mathrm{kg})$, body mass index (BMI) and waist circumference (centimetres, $\mathrm{cm}$ ) between baseline (end of the 16 weeks weight loss intervention) and 12 months (end of weight maintenance intervention).

2. Change in time (minutes) per day spent in light and moderate-to-vigorous physical activity at 12 months.

3. Change in time (minutes) spent in sedentary behaviour per day at 12 months.

\section{Measures}

At baseline and on completion of the TAKE 5 weight maintenance intervention, a research assistant met with the participant and carers to complete the measures of outcome.

\section{Anthropometric measurements}

Measurements were made in duplicate by the researcher, with the participant wearing light clothes without shoes and in triplicate if discrepancy between the two methods was observed. The weight change was calculated as the mean of the difference between the two measurements. Weight $(\mathrm{kg})$ was measured to the nearest $100 \mathrm{~g}$, using Seca 877 scales (CE approval class III; Seca, Hamburg, Germany). Height (m) was measured to the nearest $1 \mathrm{~mm}$ using the Seca Leicester stadiometer (Seca). Height (m) and weight $(\mathrm{kg})$ were used to calculate BMI, and waist measurements were made according to the WHO (2008) protocol on anthropometric measurements.

\section{Social support, ability and health status}

A purpose-designed data collection form was used to collect demographic and health data on participants at 
baseline and at 12 months. Source of information was the participants themselves if able to answer the questions or the carers for the participants that required support. The form consisted of two subsections that covered the following:

1. Section A: Social support and ability.

2. Section B: Physical health.

The level of intellectual disability was classified as mild, moderate, severe or profound. The assessment was based on a scores (5-25) obtained from five questions on the participants current ability levels in eating and drinking, in intimate care, personal safety, communication and decision making with or without support. The participants were asked about their type of support such as if they were living independently or lived with family carer or paid carer.

This questionnaire has been used before by Cooper (1997) assessing the psychiatric epidemiology in adults with intellectual disability. It has been also compared and shown to have a good level of agreement with the Vineland's Adaptive Behaviour Scale which is a validated structured assessment of functioning and ability level (Sparrow et al. 1984).

\section{Physical health}

The questionnaire included questions on health problems known to be commonly experienced by people with intellectual disability and people with obesity (Emerson 2010). These included high blood pressure, high cholesterol and type 2 diabetes. Information was based as reported by the carers based on diagnosis and prescribed medication from the GP.

\section{Physical activity measurements}

Physical activity measurements were made at the end of the weight maintenance using identical methods to the weight loss study, described in detail previously (Matthews et al. 2011; Melville et al. 2011). Physical activity was measured objectively with use of Actigraph GT1M accelerometers (Manufacturing Technology, Inc., Fort Walton Beach, FL, USA). The use of G1TM for the physical activity measurement has been validated in other studies (John et al. 2010; Kelly et al. 2013). Participants were invited to wear accelerometers for 7 days at the end of the Phase I and at the end of the Phase II. The accelerometer was worn at the hip, attached to a belt worn round the waist. Accelerometer data were expressed as three categories of physical activity intensity based on the following cut-offs points (Freedson et al. 1998):

1. Sedentary behaviour (0-499 counts/ $\mathrm{min})$.

2. Light-intensity activity (500-1951 counts/min).

3. Moderate-to-vigorous intensity activity (>1952 counts/min).

The accelerometer data for each of the three categories of activity were expressed as mean time/d in min and percentage of total monitoring time.

Additional data on walking frequency were collected using the International Physical Activity Questionnaireshort version (IPAQ-S). This type of self-report questionnaire has been used and validated in other studies and is positively accepted by investigators and respondents (Craig et al. 2003; Papathanasiou et al. 2009). Knowing the barriers that the participants with $\mathbf{Z}$ intellectual disability may have in answering questions regarding time and frequency (Finlay \& Lyons 2001), the carers were asked to assist the participant where appropriate.

\section{Statistical analysis}

All data management and statistics were performed using SPSS for windows version 18 (SPSS, Chicago, IL, USA).

Means, standard deviations (SD) for continuous variables, for example weight, BMI, waist circumference were reported with mean difference (95\% CI) and corresponding $P$ value in text. Categorical variables, for example gender were reported in number and percentage in text and tables. Analysis of normality with Kolmogorov-Smirnov test showed that weight change was normally distributed. Paired t-test analyses were used to examine within group differences of measured outcomes.

\section{Results}

Results were presented against two main points of the TAKE 5 weight management intervention:

1. Baseline (end of the 16 week weight loss phase-Phase I).

2. 12 months (end of 12 months weight maintenance phase-Phase II).

\section{Participants}

Of the 31 individuals eligible, all agreed to participate in Phase II. However, one individual died and two 
participants withdrew. One decided to follow a commercial weight management programme and one chose to take a break from weight management.

The characteristics of the 28 participants, 10 males (36\%) and 18 females (64\%) are shown in Table 1. Of the participants, none had profound intellectual disability, only one reported married, eight had Down syndrome (29\%), two were partially sighted (7\%), five had a hearing impairment $(18 \%)$ and nine reported having epilepsy (32\%). None of the participants lived independently but all lived with paid carers or family members.

\section{Study outcomes}

There was no statistically significant post-intervention change in weight $(-0.6 \mathrm{~kg} ; 95 \% \mathrm{CI}=-2.8,+1.5)$, BMI $\left(-0.1 \mathrm{~kg} / \mathrm{m}^{2} ; \quad 95 \% \quad \mathrm{CI}=-0.9, \quad+0.8\right) \quad$ and waist circumference $\quad(-0.4 \mathrm{~cm} ; 95 \% \quad \mathrm{CI}=-2.7,1.9) \quad$ at 12 months, as shown in Table 2.

Table I Demographic and health characteristics ${ }^{1}$ of participants at baseline ${ }^{2}$

\begin{tabular}{|c|c|c|}
\hline Variable & $n$ & $\%$ \\
\hline \multicolumn{3}{|l|}{ Gender } \\
\hline Male & 10 & 36 \\
\hline Female & 18 & 64 \\
\hline $5 \%$ weight loss & 18 & 64 \\
\hline $3 \%$ to $<5 \%$ weight loss & 10 & 36 \\
\hline \multicolumn{3}{|l|}{ Ethnicity } \\
\hline Caucasian & 27 & 96 \\
\hline Other Asian background & 1 & 4 \\
\hline \multicolumn{3}{|l|}{ Type of support } \\
\hline Lives independently & 1 & 4 \\
\hline Family carer & 9 & 32 \\
\hline Paid carer & 18 & 64 \\
\hline \multicolumn{3}{|c|}{ Level of intellectual disability ${ }^{3}$} \\
\hline Mild & 10 & 36 \\
\hline Moderate & 9 & 32 \\
\hline Severe & 9 & 32 \\
\hline \multicolumn{3}{|c|}{ Hypertension or raised blood pressure ${ }^{4}$} \\
\hline Yes & 7 & 25 \\
\hline \multicolumn{3}{|l|}{ High cholesterol $^{4}$} \\
\hline Yes & 6 & 21 \\
\hline \multicolumn{3}{|l|}{ Type 2 diabetes ${ }^{4}$} \\
\hline Yes & 2 & 7 \\
\hline
\end{tabular}

${ }^{1}$ Data as number of participants and percentages, $n=28$.

${ }^{2}$ End of Phase I.

${ }^{3}$ The assessment of level of intellectual disability is described in Melville et al. (2011).

${ }^{4}$ As reported by the carers based on diagnosis and prescribed medication from the GP.
At Phase I, 18 (64\%) participants achieved a 5\% weight loss. There was no statistically significant weight change $(P<0.05)$ at Phase II for participants that achieved a $5 \%$ weight loss at Phase I $(+0.3 \mathrm{~kg} ; 95 \%$ $\mathrm{CI}=-2.7,3.4)$ or for those participants that did not achieve a $5 \%$ weight loss $(-2.3 \mathrm{~kg} ; \mathrm{CI}=-5.0,0.4)$.

In addition, there was no statistically significant difference $(P<0.05)$ in weight change at Phase 2 between males $(-2.2 \mathrm{~kg}, 95 \% \mathrm{CI}=-6.9,2.5)$ and females $(+0.3 \mathrm{~kg}$; 95\% CI $=-2.1,2.7)$.

\section{Weight maintenance}

Using the Stevens et al. (2006) definition for weight loss maintenance, the participants were classified in three categories based on weight changes between end of Phase I and end of Phase II:

1. Participants that had a weight gain of $>3 \%$.

2. Participants who maintained their weight $\leq 3 \%$.

3. Participants that had a weight loss of $>3 \%$.

Table 3 shows the numbers and percentages identified in each category with the mean weight change in $\mathrm{kg}$ and SD at 12 months.

Around half of the participants $(50 \%)$ maintained their weight (mean weight change $-0.5 \mathrm{~kg}$, SD 2.2) within $\pm 3 \%$ from initial body weight at baseline, eight participants $(29 \%)$ gained weight (mean weight gain $+5.4 \mathrm{~kg}$, SD 2.2) and six participants lost weight (mean weight loss $-8 \mathrm{~kg}$, SD 3.0).

\section{Change in physical activity}

Accelerometer data at baseline and 12 months were available and eligible for inclusion in the analysis from 18 of the 28 participants. At 12 months, data from 10 participants were excluded due to a lack of recordings or recordings for $<3$ days and failure to wear the accelerometers at both time points. Issues with the use of accelerometers included: participants forgot to wear the accelerometers or they would remove them when in day centres or carers forgot to remind them to wear them.

\section{Sedentary behaviour}

Objective measurements collected from the accelerometers showed that participants lead sedentary lifestyles at baseline and at the end of the 12 months of the weight loss maintenance intervention. At the end of weight maintenance, intervention participants were spending a mean of $555.3 \mathrm{~min} /$ day (SD 139.6) in 
Table 2 Weight $(\mathrm{kg})$, WC $(\mathrm{cm})$ and BMI $\left(\mathrm{kg} / \mathrm{m}^{2}\right)^{1}$ at baseline and 12 months and differences in outcome measures at 12 months

\begin{tabular}{|c|c|c|c|c|c|c|c|}
\hline \multirow[b]{2}{*}{ Outcome } & \multicolumn{2}{|c|}{ Baseline $^{2}$} & \multicolumn{2}{|c|}{12 months } & \multirow{2}{*}{$\begin{array}{l}\text { Mean diff. } \\
(12 \text { months - baseline) }\end{array}$} & \multirow[b]{2}{*}{$S D$} & \multirow[b]{2}{*}{$P^{*}$} \\
\hline & Mean & $S D$ & Mean & $S D$ & & & \\
\hline Change in weight $(\mathrm{kg})$ & 94.8 & 22.2 & 94.2 & 21.6 & -0.6 & 5.5 & 0.5 \\
\hline Change in WC $(\mathrm{cm})$ & 113.2 & 14.5 & 112.8 & 15.6 & -0.4 & 5.7 & 0.7 \\
\hline Change in BMI $\left(\mathrm{kg} / \mathrm{m}^{2}\right)$ & 38.2 & 7.6 & 38.1 & 7.9 & -0.06 & 2.2 & 0.8 \\
\hline
\end{tabular}

${ }^{1}$ Data as mean values and standard deviation, analysis set; $n=28$ for BMI and weight, $n=27$ for WC.

${ }^{2}$ End of Phase I.

‡Statistically significant difference between 12 months and baseline.

Table 3 Categories of weight changes ${ }^{1}$ between baseline ${ }^{2}$ and 12 months

\begin{tabular}{lccr}
\hline Weight change & $\begin{array}{c}12 \text { monthsn } \\
(\%)\end{array}$ & $\begin{array}{c}\text { Mean weight }(\mathrm{kg}) \\
\text { change at 12 months }\end{array}$ & SD \\
\hline Weight gain $>3 \%$ & $8(29)$ & +5.4 & 2.2 \\
Weight maintenance & $14(50)$ & -0.5 & 1.8 \\
Weight loss $>3 \%$ & $6(21)$ & -8.0 & 3.0 \\
\hline
\end{tabular}

sedentary behaviour or a $80 \%$ (SD 6.8) of the time spent wearing the accelerometers.

There was no statistically significant decrease $(P=0.7)$ in the percentage of time spent in sedentary behaviour between baseline and 12 months, as shown in Table 4 .

\section{Light physical activity}

At the end of the weight loss maintenance intervention, participants were spending 94.9 (SD 38.8) minutes per day in light physical activity, equal to $13 \%$ of the monitored time. There was no statistically significant increase in time spend in light physical activity $(P=0.09)$ (Table 4).

\section{Moderate-to-vigorous physical activity}

There was no statistically significant increase of time or percentage of time spent in moderate-to-vigorous physical activity at 12 months $(P=0.2)$. Participants were spending only $3 \%$ (SD 1.7 ) (21.8 $\mathrm{min}$ ) of the recorded time in this type of physical activity (Table 4).

\section{Walking}

IPAQ data on walking were available for all participants $(n=28)$ at baseline and 12 months. According to
Table 4, at 12 months, participants spent less days (mean days 4.5, SD 2.3) walking (at least $10 \mathrm{~min}$ per day) than at baseline (mean days 5.5, SD 2.1) $(P<0.05)$.

\section{Discussion}

A clinically significant weight loss and long-term weight loss maintenance can have a positive impact on the impaired health-related quality of life of adults with obesity (Blissmer et al. 2006; Karlsson et al. 2007). The TAKE 5 weight management intervention for adults with intellectual disability and obesity is a multicomponent intervention that included distinct weight loss phase and weight maintenance phases. According to the findings of this study, the majority of the participants maintained their weight loss for 12 months after the weight loss phase.

\section{Weight maintenance}

Few studies have examined weight maintenance in individuals with intellectual disability and methodological differences make the comparison to this study difficult (Spanos et al. 2013a,b). For example, Saunders et al. (2011) the only other multicomponent weight loss intervention in adults with intellectual disability that included a weight loss maintenance phase used different:

1. Duration of the weight maintenance interventions (6 months versus 12 months).

2. Type of initial weight loss intervention (1200 kcal/ $5024 \mathrm{~kJ}$ diet versus $600 \mathrm{kcal} / 2512 \mathrm{~kJ}$ energy deficit diet).

3. Intensity of the weight maintenance phase (monthly meetings with $24 \mathrm{hr}$ dietary recalls versus monthly meetings with extensive behavioural and health education). 
Table 4 Physical activity and walking ${ }^{1}$ at baseline ${ }^{2}$ and 12 months and physical activity and walking changes at 12 months

\begin{tabular}{|c|c|c|c|c|c|c|c|}
\hline \multirow[b]{2}{*}{ Outcome } & \multicolumn{2}{|c|}{ Baseline $^{2}$} & \multicolumn{2}{|c|}{12 months } & \multirow{2}{*}{$\begin{array}{l}\text { Mean dif. } \\
\text { (12 months - baseline) }\end{array}$} & \multirow[b]{2}{*}{$S D$} & \multirow[b]{2}{*}{$P^{*}$} \\
\hline & Mean & $S D$ & Mean & $S D$ & & & \\
\hline $\begin{array}{l}\text { Time spent (min) in light-intensity } \\
\text { physical activity/d }\end{array}$ & 82.6 & 38.2 & 94.9 & 38.8 & 12.4 & 29.7 & 0.09 \\
\hline $\begin{array}{l}\text { Time spent (min) in moderate-to-vigorous } \\
\text { intensity physical activity/d }\end{array}$ & 19.3 & 17.3 & 21.9 & 14.0 & 2.6 & 11.8 & 0.2 \\
\hline Time spent ( $\mathrm{min}$ ) in sedentary behaviour/d & 576.5 & 145.9 & 555.3 & 139.6 & -21.2 & 221.2 & 0.7 \\
\hline $\begin{array}{l}\text { Percentage of time spent in light- } \\
\text { intensity physical activity }\end{array}$ & 12.6 & 6.2 & 12.7 & 4.5 & 0.03 & 4.8 & 0.9 \\
\hline $\begin{array}{l}\text { Percentage of time spent in } \\
\text { moderate-to-vigorous intensity physical activity }\end{array}$ & 3.2 & 3.6 & 2.8 & 1.7 & -0.4 & 2.9 & 0.6 \\
\hline Percentage of time spent in sedentary physical behaviour & 84.2 & 8.7 & 79.8 & 6.8 & -4.3 & 9.3 & 0.06 \\
\hline $\begin{array}{l}\text { Number of days spend walking } \\
\text { at least } 10 \text { minutes at a time in previous } 7 \text { days }\end{array}$ & 5.5 & 2.2 & 4.5 & 2.3 & -1.0 & 2.5 & 0.04 \\
\hline Time spent (min) walking in one of these days & 60.3 & 55.0 & 75.5 & 65.5 & 15.2 & 72.4 & 0.3 \\
\hline
\end{tabular}

${ }^{1}$ Data as mean values and standard deviations, analysis set for physical activity - accelerometer; $n=18$ and analysis set for walking - IPAQ; $n=28$.

${ }^{2}$ End of Phase I.

${ }^{\ddagger}$ Statistically significant difference between 12 months and baseline.

Contrary to this study, Saunders et al. (2011) reported weight maintenance in reference to baseline and did not use a definition for weight maintenance, reporting results as a mean of weight loss and weight gain, with a total $9.4 \%$ weight loss of baseline.

\section{Diet}

The diet used for both phases of the TAKE weight management programme was based on the principles of a healthy balanced diet, recommending healthy portions of foods from all the food groups but avoiding significant changes that could challenge the routine and the compliance of an individual with intellectual disability (Emerson \& Baines 2010; Wynne et al. 2005). A qualitative analysis of the TAKE 5 Phase I showed that the diet prescription and the pictorial tools used for education on healthy diet were embraced by the participants and their carers, assisting them to understand the principles of the healthy balanced diet (Spanos et al. 2013a,b).

The form of dietary advice offered to participants remained constant throughout the two phases of the study, weight loss and weight maintenance, although the quantities of food advocated to the individuals differed. This study did not attempt to assess the compliance of the participants to the dietary recommendations. Given the difficulties of assessing usual diet in adults with intellectual disability (Humphries et al. 2008) our only proxy for dietary compliance was body weight. The advice appeared to have been understood by both carers and participants, although the presence of weight loss and gain in a number of participants would indicated a less than optimal level of compliance.

\section{Physical activity}

Objective measurements of physical activity (accelerometers) showed that the TAKE 5 weight maintenance intervention did not have a significant effect on physical activity levels or sedentary behaviours. No participants in the current study met current physical activity recommendations (NICE 2006; SIGN 2010; Chief Medical Officer 2011) after the weight loss maintenance phase. These findings are surprising given the significant proportion of participants who maintained their weight. There was a significant amount of missing accelerometer data at 12 months which may have an influence on the results.

Our findings are novel, as no multicomponent or single component weight management intervention for adults with intellectual disability that provided a weight maintenance intervention has assessed the physical 
activity levels of the participants (Fox et al. 1984, 1985; McCarran \& Andrasik 1990; Saunders et al. 2011). In addition, in previous studies, the detail of information regarding advice on physical activity during the weight maintenance phase was scant and insufficient to allow replication of the advice. Only Fox et al. (1985) reported using reward systems to encourage changes in physical activity but similar to other studies did not assess the activity levels.

It possible that the TAKE 5 weight maintenance intervention was unable to overcome commonly reported barriers to physical activity and walking by people with intellectual disability and their carers including costs, participant's lack of knowledge of types of available physical activities and lack of understanding the benefits of physical activity (Hawkins \& Look 2006; Mahy et al. 2010) and weather (Temple 2007). In a recent study by Caton et al. (2012), adults with intellectual disability reported joining walking clubs at day centres but the regularity doing the activity was uncertain and the lack of support from carers was identified as a barrier for the participants to go for a walk.

TAKE 5 aimed to improve the physical activity levels of the participants by providing advice on ways of overcoming potential barriers including advice to participate in suitable exercise programmes running at the day centres they attended and planning activities for their weekly routine. However, modifiable barriers to physical activity for people with intellectual disability such as lack of social support because of limitations in planning, transportation and staffing can be related to the lack of funding, policies and protocols of residential and day service programmes (Bodde \& Seo 2009). These barriers can be difficult to be addressed just by a weight maintenance intervention and may require the substantial contribution of managers of care plans for a holistic restructure of the support of an individual with intellectual disability.

As increasing levels of physical activity are central to successful weight maintenance (NICE 2006; SIGN 2010), future studies of multicomponent weight management programmes for adults with intellectual disability should explore innovative ways to support participants to progressively increase levels of physical activity.

\section{Limitations and strengths}

The single stranded study was useful to determine the utility of this novel programme. Hence, no sample size calculation was undertaken, or control group recruited
(Loveman et al. 2011), so the results in this study should be treated with a degree of caution. As with any study, a control group that did not receive an intervention could provide a robust evaluation of the weight maintenance phase (Stanley 2007). However, the TAKE 5 management programme was a feasibility study, first of its nature that would provide the evidence to justify a larger RCT (Melville et al. 2011). Cost-effectiveness, an important aspect to show the potentials of this intervention in real community or clinical settings (Loveman et al. 2011), could be examined in the context of an RCT, with a control group receiving 'care as usual' as defined by the local health services. It has to be noted that another RCT study has currently started exploring these research areas in intellectual disability in depth, potentially providing valid evidence on cost-effectiveness analysis and an estimation of the treatment effect on weight (Beeken et al. 2013).

Knowing the barriers that the participants with intellectual disability may have in answering IPAQ questions regarding time and frequency (Finlay \& Lyons 2001), often paid carers were asked to assist the participant where appropriate. However, this may have allowed potential errors due to recall errors from the carers and the participants. It is possible that paid carers, who differ in the amount of time they spend with individuals over any week, may have underestimated or overestimated the walking frequency of the participants due to lack of information from other colleagues who supported the participants in the previous 7 days.

The health benefits of walking include primary and secondary prevention of cardiovascular disease (Murphy et al. 2007), in some cases modest weight loss (Richardson et al. 2008) and prevention of weight regain (Klem et al. 1997; Villanova et al. 2006; Nakade et al. 2012). However, the effects of walking on weight control depend on the total duration of the exercise and on the pace of walking (Votruba et al. 2000; Donnelly et al. 2009). The TAKE 5 promoted walking as a physical activity but did not collect any information regarding the pace of the walk, for example brisk walking or the distance achieved each day. Walking can be assessed with the use of pedometers but in adults that walk in a slow pace, measurements of steps can be inaccurate (Cyarto et al. 2004). This means that walking needs to be assessed with recent and potentially more valid methods such as a combination of physical activity diaries, accelerometers and global positioning systems (GPS) (Bassett 2012). 
This study highlighted the importance of providing a service that is suitable to the cognitive and communication needs of people with intellectual disability. Therefore, the materials used in this study were designed based on recommendations on simplification of information using pictorial explanations. In addition, the researcher was trained in the use of augmentative communication (Murphy 2006) and used a photo-library specially developed for people with intellectual disability allowing the participants to express their feelings and show their knowledge. It would be valuable for the study if advocacy groups and service users or accessible information workers were approached at an early stage to evaluate the construction and layout of the materials used in the intervention (Ward \& Townsley 2005). However, the technique used in the materials, and the technique of communication in the weight maintenance intervention was already tested and assessed during the

9 TAKE 5 weight loss intervention (Spanos et al. 2012).

There is lack of extensive information in this study on the participants' living arrangements and the impact these factors could have on weight maintenance. The environment that an individual lives in and the type of support provided to this person can play an important role in the prevalence and the treatment of obesity

10 (Emmerson et al. 2004; Rimmer \& Yamaki 2006). For example, people with intellectual disability that live in family homes have a greater access to food availability than those who live in restrictive accommodations supported by paid carers (Geller \& Crowley 2009). Bryan et al. (2000) assessed the nutritional vulnerability of people with intellectual disability in the community by measuring weight changes after 1 year of discharge from institutions. The level of overweight for males and females increased within 1 year by six per cent and five per cent, respectively.

In addition, people with intellectual disability are more likely to be obese when they live in settings where the service user has a tenancy, less sophisticated procedures are in place for the support of the resident and with less senior staff ratio (Robertson et al. 2000). It is suggested that families may facilitate psychological support for people with intellectual disability in weight management interventions better than paid carers (Geller \& Crowley 2009). The small sample size could have affected the power of identifying any correlations between socio-clinical characteristics and weight maintenance. Underpowered studies with small samples cannot lead to real predictors of outcome (Van Voorhis \& Morgan 2007; Stubbs et al. 2011).

\section{Conclusion}

The long-term effectiveness of a multicomponent weight management programme in adults without intellectual disability may rely on the holistic approach of the programme to promote changes to all crucial areas of weight management. These changes must be simple and acceptable by individuals to be sustainable. This structured multicomponent weight maintenance intervention provides first evidence on weight maintenance in adults with intellectual disability. Revisions to the physical activity component of the TAKE 5 weight management programme are required. Controlled studies re-examining the effectiveness of weight management programmes including weight loss and weight maintenance phases should be considered.

\section{Acknowledgments}

The present authors would like to thank the study participants and family and paid carers. The present authors would also like to thank the Glasgow and Clyde Weight Management Service. The research was funded by the Equally Well Programme, Adult Care and Support Division, Scottish Government.

\section{Correspondence}

Any correspondence should be directed to Catherine R. Hankey, Senior Lecturer, Human Nutrition, College of Medical, Veterinary and Medical and Life Sciences, University of Glasgow, Level 2, New Lister Building, Glasgow Royal Infirmary, Glasgow G31 2ER, UK (e-mail: catherine.hankey@glasgow.ac.uk).

\section{References}

Bartlo P. \& Klein P. J. (2011) Physical activity benefits and needs in adults with intellectual disabilities: systematic review of the literature. American Journal on Intellectual and Developmental Disabilities 116, 220-232.

Bassett D. R. (2012) Device-based monitoring in physical activity and public health research. Physiological Measurement 33, 1769-1783.

Beeken R. J., Spanos D., Fovargue S., Hunter R., Omar R., Hassiotis A., King M., Wardle J. \& Helen Croker H. (2013) Piloting a manualised weight management programme (Shape Up-LD) for overweight and obese persons with mildmoderate learning disabilities: study protocol for a pilot randomised controlled trial. Trials ????, ????. Available at: http:/ / www.trialsjournal.com/content/14/1/71 (Accessed on 01 June 2014). 
Blissmer B., Riebe D., Dye G., Ruggiero L., Greene G. \& Caldwell M. (2006) Health-related quality of life following a clinical weight loss intervention among overweight and obese adults: intervention and 24 month follow-up effects. Health and Quality of Life Outcomes 4, 43.

Bodde A. E. \& Seo D. C. (2009) A review of social and environmental barriers to physical activity for adults with intellectual disabilities. Disability and Health Journal 2, 57-66.

Braunschweig C. L., Gomez S., Sheean P., Tomey K. M., Rimmer J. \& Heller T. (2004) Nutritional status and risk factors for chronic disease in urban-dwelling adults with Down syndrome. American Journal of Mental Retardation 109, 186-193.

Brewster S. J. (2004) Putting words into their mouths? Interviewing people with learning disabilities and little/no speech. British Journal of Learning Disabilities 32, 166-169.

Bryan F., Allan T. \& Russell L. (2000) The move from a longstay learning disabilities hospital to community homes: a comparison of clients' nutritional status. Journal of Human Nutrition and Dietetics 13, 265-270.

Butryn M. L., Phelan S., Hill J. O. \& Wing R. R. (2007) Consistent self-monitoring of weight: a key component of successful weight loss maintenance. Obesity 15, 3091-3096.

Catenacci V. A. \& Wyatt H. R. (2007) The role of physical activity in producing and maintaining weight loss. Nature Clinical Practice Endocrinology \& Metabolism 3, 518-529.

Caton S., Chadwick D., Chapman M., Turnbull S., Mitchell D. \& Stansfield J. (2012) Healthy lifestyles for adults with intellectual disability: knowledge, barriers, and facilitators. Journal of Intellectual and Developmental Disability 37, 248-259.

Chief Medical Officer (CMO). (2011) Start Active, Stay Active: A Report on Physical Activity for Health from the Four Home Countries. Chief Medical Officers, DH, London.

Collins C., Neve M., Morgan P., Fletcher K., Williams R., Myles Y. \& Callister R. (2010) Effectiveness of interventions with a dietary component on weight loss maintenance: a systematic review. Joanna Briggs Institute Library of Systematic Reviews 24, S11-S28.

Cooper S. A. (1997) Epidemiology of psychiatric disorders in elderly compared with younger adults with learning disabilities. British Journal of Psychiatry 170, 375-380.

Craig C. L., Marshall A. L., Sjostrom M., Bauman A. E., Booth M. L., Ainsworth B. E., Pratt M., Ekelund U., Yngve A., Sallis J. F. \& Oja P. (2003) International physical activity questionnaire: 12-country reliability and validity. Medicine and Science in Sports and Exercise 35, 1381-1395.

Cyarto E. V., Moorhead G. E. \& Brown W. J. (2004) Updating the evidence relating to physical activity intervention studies in older people. Journal of Science and Medicine in Sport 7, 3038.

Department of Health Government of United Kingdom The Eatwell Plate. Available at: http://webarchive.nationalarchi ves.gov.uk/20130107105354/http://www.dh.gov.uk/en/Pub lichealth/Nutrition/DH_126493\#_1 (Accessed on 01 June 2014).
Donnelly J. E., Blair S. N., Jakicic J. M., Manore M. M., Rankin J. W. \& Smith B. K. (2009) American College of Sports Medicine Position Stand. Appropriate physical activity intervention strategies for weight loss and prevention of weight regain for adults. Medicine and Science in Sports Exercise 41, 459-471.

Draheim C. C. (2006) Cardiovascular disease prevalence and risk factors of persons with mental retardation. Mental Retardation and Developmental Disabilities Research Reviews 12, 3-12.

Draheim C. C., Williams D. P. \& McCubbin J. A. (2002) Physical activity, dietary intake, and the insulin resistance syndrome in nondiabetic adults with mental retardation. American Journal Mental Retardation 107, 361-375.

Emerson E. (2005) Underweight, obesity and exercise among adults with intellectual disabilities in supported accommodation in Northern England. Journal of Developmental and Physical Disabilities 49, 134-143.

Emerson E. B. S. (2010) Health Inequalities and People with Learning Disabilities in the UK: 2010. Improving Health and Lives: Learning Disabilities Observatory, Durham.

Emerson E. \& Baines S. (2010) The estimated prevalence of autism among adults with learning disabilities in England. Available at: http://www.improvinghealthandlives.org.uk/ publications (Accessed 17/01/2015)

Farooqi I. S. \& O'Rahilly S. (2005) New advances in the genetics of early onset obesity. International Journal of Obesity 29, 1149-1152.

Ferland A. \& Eckel R. H. (2011) Does sustained weight loss reverse the metabolic syndrome? Current Hypertension Reports 13, 456-464.

Finlay W. M. \& Lyons E. (2001) Methodological issues in interviewing and using self-report questionnaires with people with mental retardation. Psychological Assessment 3, 319-335.

Fox R. A., Haniotes H. \& Rotatori A. (1984) A streamlined weight loss program for moderately retarded adults in a sheltered workshop setting. Applied Research in Mental Retardation 5, 69-79.

Fox R. A., Rosenberg R. \& Rotatori A. F. (1985) Parent involvement in a treatment program for obese retarded adults. Journal of Behavior Therapy and Experimental Psychiatry 16, 45-48.

Freedson P. S., Melanson E. \& Sirard J. (1998) Calibration of the Computer Science and Applications Inc. Accelerometer. Medicine and Science in Sports and Exercise 30, 777-781.

Geller J. \& Crowley M. (2009) An empowerment group visit model as treatment for obesity in developmentally delayed adults. Journal of Developmental and Physical Disabilities 21, 345-353.

Haveman M., Heller T., Lee L., Maaskant M., Shooshtari S. \& Strydom A. (2010) Major health risks in aging persons with intellectual disabilities: an overview of recent studies. Journal of Policy and Practice in Intellectual Disabilities 7, 59-69.

Havercamp S. M., Scandlin D. \& Roth M. (2004) Health disparities among adults with developmental disabilities, 
adults with other disabilities, and adults not reporting disability in North Carolina. Public Health Reports 119, 418426.

Hawkins A. \& Look R. (2006) Levels of engagement and barriers to physical activity in a population of adults with learning disabilities. British Journal of Learning Disabilities 34, 220-226.

Hove O. (2004) Weight survey on adult persons with mental retardation living in the community. Research in Developmental Disabilities 25, 9-17.

Humphries K., Traci M. A. \& Seekins T. (2008) Food on film: pilot test of an innovative method for recording food intake of adults with intellectual disabilities living in the community. Journal of Applied Research in Intellectual Disabilities 21, 168-173.

International Physical Activity Questionnaire. Available at: http://www.ipaq.ki.se/ipaq.htm. (Accessed on 01 March 2014).

Jeffery R. W., Drewnowski A., Epstein L. H., Stunkard A. J., Wilson G. T., Wing R. R. \& Hill D. R. (2000) Long-term maintenance of weight loss: current status. Health Psychology 19, 5-16.

John D., Tyo B. \& Bassett D. R. (2010) Comparison of four actigraph accelerometers during walking and running. Medicine and Science in Sports and Exercise 42, 368-374.

Karlsson J., Taft C., Ryden A., Sjostrom L. \& Sullivan M. (2007) Ten-year trends in health-related quality of life after surgical and conventional treatment for severe obesity: the SOS intervention study. International Journal of Obesity 31, 12481261.

Kelly L. A., McMillan D. G., Anderson A., Fippinger M., Fillerup G. \& Rider J. (2013) Validity of actigraphs uniaxial and triaxial accelerometers for assessment of physical activity in adults in laboratory conditions. Biomedical Central Medical Physics 13, 5.

Klem M. L., Wing R. R., McGuire M. T., Seagle H. M. \& Hill J. O. (1997) A descriptive study of individuals successful at long-term maintenance of substantial weight loss. American Journal of Clinical Nutrition 66, 239-246.

Loveman E., Frampton G. K., Shepherd J., Picot J., Cooper K., Bryant J., Welch K. \& Clegg A. (2011) The clinical effectiveness and cost-effectiveness of long-term weight management schemes for adults: a systematic review. Health Technology Assessment 15, 1-182.

Maaskant M. A., Van Knijff-Raeven A. G. M., Van Schrojenstein Lantman-de Valk H. M. J. \& Veenstra M. Y. (2009) Weight status of persons with intellectual disabilities. Journal of Applied Research in Intellectual Disabilities 22, 426-432.

Mahy J., Shields N., Taylor N. F. \& Dodd K. J. (2010) Identifying facilitators and barriers to physical activity for adults with Down syndrome. Journal of Intellectual Disability Research 54, 795-805.

Matthews L., Hankey C., Penpraze V., Boyle S., Macmillan S., Miller S., Murray H., Pert C., Spanos D., Robinson N. \& Melville C. A. (2011) Agreement of accelerometer and a physical activity questionnaire in adults with intellectual disabilities. Preventive Medicine 52, 361-364.

McCarran M. S. \& Andrasik F. (1990) Behavioral weight-loss for multiply-handicapped adults: assessing caretaker involvement and measures of behaviour change. Addictive Behaviours 15, 13-20.

Melville C. A., Boyle S., Miller S., Macmillan S., Penpraze V., Pert C., Spanos D., Matthews L., Robinson N., Murray H. \& Hankey C. R. (2011) An open study of the effectiveness of a multi-component weight-loss intervention for adults with intellectual disabilities and obesity. British Journal of Nutrition 105, 1553-1562.

Michie S., Abraham C., Whittington C., McAteer J. \& Gupta S. (2009) Effective techniques in healthy eating and physical activity interventions: a meta-regression. Health Psychology 6, 690-701.

Morrison D. S., Boyle S., Morrison C., Allardice G., Greenlaw N. \& Forde L. (2012) Evaluation of the first phase of a specialist weight management programme in the UK National Health Service: prospective cohort study. Public Health Nutrition 15, 28-38.

Murphy J. (2006) Perceptions of communication between people with communication disability and general practice staff. Health Expectations 9, 49-59.

Murphy M. H., Nevill A. M., Murtagh E. M. \& Holder R. L. (2007) The effect of walking on fitness, fatness and resting blood pressure: a meta-analysis of randomised, controlled trials. Preventive Medicine 4, 377-385.

Nakade M., Aiba N., Suda N., Morita A., Miyachi M., Sasaki S. \& Watanabe S. (2012) SCOP Group. Behavioral change during weight loss program and one-year follow-up: Saku Control Obesity Program (SCOP) in Japan. Asia Pacific Journal of Clinical Nutrition 21, 22-34.

National Institute for Health and Clinical Excellence. (2006) Obesity: The Prevention, Identification, Assessment and Management of Overweight and Obesity in Adults and Children. NICE, London.

Richardson C. R., Newton T. L., Abraham J. J., Sen A., Jimbo M. \& Swartz A. M. (2008) A meta-analysis of pedometerbased walking interventions and weight loss. Annals of Family Medicine 6, 69-77.

Rimmer J. H. \& Yamaki K. (2006) Obesity and intellectual disability. Mental Retardation and Developmental Disabilities Research Reviews 12, 22-27.

Robertson J., Emerson E., Gregory N., Hatto C., Turner S., Kessissoglou S. \& Hallam A. (2000) Lifestyle related risk factors for poor health in residential settings for people with intellectual disabilities. Research in Developmental Disabilities 21, 469-486.

Robertson J., Emerson E., Baines S. \& Hatton C. (2014) Obesity and health behaviours of British adults with self-reported intellectual impairments: cross sectional survey. BMC Public Health 14, 219.

Saunders R. R., Saunders M. D., Donnelly J. E., Smith B. K., Sullivan D. K., Guilford B. \& Rondon M. F. (2011) Evaluation 
of an approach to weight loss in adults with intellectual or developmental disabilities. Intellectual and Developmental Disabilities 49, 103-112.

Scientific Advisory Committee on Nutrition (SACN). (2011) Dietary Reference Values for Energy. The Stationery Office, London.

Scottish Executive. (2000) The Adults with Incapacity (Scotland) Act. Scottish Executive, Edinburgh.

Scottish Intercollegiate Guidelines Network. (2010) Management of Obesity: A National Clinical Guideline. SIGN, Edinburgh.

Sherwood N. E., Jeffery R. W., French S. A., Hannan P. J. \& Murray D. M. (2000) Predictors of weight gain in the Pound of Prevention study. International Journal of Obesity and Related

13 Metabolic Disorders 24, 395-403.

Spanos D., Hankey C. R., Boyle S., Koshy P., Macmillan S., Matthews L., Miller S., Penpraze V., Pert C., Robinson N. \& Melville C. A. (2013a) Carers' perspectives of a weight loss intervention for adults with intellectual disabilities and obesity: a qualitative study. Journal of Intellectual Disability Research 57, 90-102.

Spanos D., Melville C. A. \& Hankey C. R. (2013b) Weight management interventions in adults with intellectual disabilities and obesity: a systematic review of the evidence. Nutrition Journal 12, 132.

Sparrow S. S., Balla D. A. \& Cicchetti D. V. (1984) Obtaining raw scores and derived scores. In: A Revision of the Vinelands Social Maturity Scale (ed. E. A. Doll), pp. 89-109. American Guidance Service, Inc., Minneapolis, MN.

Stancliffe R. J., Lakin K. C., Larson S., Engler J., Bershadsky J., Taub S., Fortune J. \& Ticha R. (2011) Overweight and obesity among adults with intellectual disabilities who use intellectual disability/developmental disability services in 20 US States. American Journal on Intellectual and Developmental Disabilities 116, 401-418.

Stanley K. (2007) Design of randomized controlled trials. Circulation 115, 1164-1169.

Stevens J., Truesdale K. P., McClain J. E. \& Cai J. (2006) The definition of weight maintenance. International Journal of Obesity 30, 391-399.

Straetmans J. M., van Schrojenstein Lantman-de Valk H. M., Schellevis F. G. \& Dinant G. J. (2007) Health problems of people with intellectual disabilities: the impact for general practice. The British Journal of General Practice: The Journal of the Royal College of General Practitioner 57, 64-66.

Stubbs J., Whybrow S., Teixeira P., Blundell J., Lawton C., Westenhoefer J., Engel D., Shepherd R., McConnon A., Gilbert P. \& Raats M. (2011) Problems in identifying predictors and correlates of weight loss and maintenance: implications for weight control therapies based on behaviour change. Obesity Reviews 12, 688-708.

Temple V. A. (2007) Barriers, enjoyment, and preference for physical activity among adults with intellectual disability. International Journal of Rehabilitation Research 30, 281-287.

Van Voorhis C. R. W. \& Morgan B. L. (2007) Understanding power and rules of thumb for determining sample sizes. Tutorials in Quantitative Methods for Psychology 3, 43-50.

Villanova N., Pasqui F., Burzacchini S., Forlani G., Manini R., Suppini A., Melchionda N. \& Marchesini G. (2006) A physical activity program to reinforce weight maintenance following a behavior program in overweight/obese subjects. International Journal of Obesity 30, 697-703.

Votruba S. B., Horvitz M. A. \& Schoeller D. A. (2000) The role of exercise in the treatment of obesity. Nutrition 16, 179-188.

Wadden T. A., Butryn M. L. \& Byrne K. J. (2004) Efficacy of lifestyle modification for long-term weight control. Obesity Research 12, 151S-162S.

Ward L. \& Townsley R. (2005) It's about a dialogue...' Working with people with learning difficulties to develop accessible information. British Journal of Learning Disabilities 33, 59-64.

Wing R. R. \& Phelan S. (2005) Long-term weight loss maintenance. The American Journal of Clinical Nutrition 82, 222S-225S.

World Health Organisation. (1985) Energy and protein requirements. Report of a joint $\mathrm{FAO} / \mathrm{WHO} / \mathrm{UNU}$ Expert Consultation. Technical Report Ser. 724, 1-206, WHO, Geneva.

World Health Organisation. (2008) Waist Circumference and Waist-Hip Ratio: Report of a WHO Expert Consultation. WHO, Geneva.

Wynne K., Stanley S., McGowan B. \& Bloom S. (2005) Appetite control. The Journal of Endocrinology 184, 291-318.

Yamaki K. (2005) Body weight status among adults with intellectual disability in the community. Mental Retardation 43, $1-10$. 


\section{Author Query Form}

\section{Journal: JAR}

Article: 12181

Dear Author,

During the copy-editing of your paper, the following queries arose. Please respond to these by marking up your proofs with the necessary changes/additions. Please write your answers on the query sheet if there is insufficient space on the page proofs. Please write clearly and follow the conventions shown on the attached corrections sheet. If returning the proof by fax do not write too close to the paper's edge. Please remember that illegible mark-ups may delay publication.

Many thanks for your assistance.

\begin{tabular}{|c|c|c|}
\hline Query reference & Query & Remarks \\
\hline 1 & WILEY: Please supply date of acceptance. & \\
\hline 2 & $\begin{array}{l}\text { AUTHOR: Please confirm that given names (red) and surnames/family names } \\
\text { (green) have been identified correctly. }\end{array}$ & \\
\hline 3 & AUTHOR: Please check that authors and their affiliations are correct. & \\
\hline 4 & $\begin{array}{l}\text { AUTHOR: Please check whether Spanos et al. } 2013 \text { belongs to 2013a or } \\
\text { 2013b. }\end{array}$ & \\
\hline 5 & $\begin{array}{l}\text { AUTHOR: Please suggest whether the term " } 12 \text { monthly" can be changed to } \\
\text { "12 monthly group sessions" in the sentence "The intervention was } \\
\text { delivered...(40-50 minutes each)." }\end{array}$ & \\
\hline 6 & $\begin{array}{l}\text { AUTHOR: Verheijden et al. } 2005 \text { has not been included in the Reference } \\
\text { List, please supply full publication details. }\end{array}$ & \\
\hline 7 & $\begin{array}{l}\text { AUTHOR: Papathanasiou et al. } 2009 \text { has not been included in the Reference } \\
\text { List, please supply full publication details. }\end{array}$ & \\
\hline 8 & AUTHOR: Please define footnote " 1 and $2 "$ in Table 3. & \\
\hline 9 & $\begin{array}{l}\text { AUTHOR: Spanos et al. } 2012 \text { has not been included in the Reference List, } \\
\text { please supply full publication details. }\end{array}$ & \\
\hline 10 & $\begin{array}{l}\text { AUTHOR: Emmerson et al. } 2004 \text { has not been included in the Reference List, } \\
\text { please supply full publication details. }\end{array}$ & \\
\hline 11 & $\begin{array}{l}\text { AUTHOR: Please provide the volume number, page range for reference } \\
\text { Beeken et al. (2013). }\end{array}$ & \\
\hline 12 & $\begin{array}{l}\text { AUTHOR: Emerson (2005) has not been cited in the text. Please indicate } \\
\text { where it should be cited; or delete from the Reference List. }\end{array}$ & \\
\hline 13 & $\begin{array}{l}\text { AUTHOR: Sherwood et al. (2000) has not been cited in the text. Please } \\
\text { indicate where it should be cited; or delete from the Reference List. }\end{array}$ & \\
\hline
\end{tabular}

